\title{
En sus voces: Testimonios orales de femicidas
}

Ruth Nohemí Rojas Icabalzeta Docente de la Universidad Nacional Autónoma de Nicaragua, Managua. nahomyrojas21@gmail.com

Fecha de recibido: 6 de abril de 2015

\section{ABSTRACT}

The need to contain the phenomenon of the femicidio opposite to a culture with scanty education that points at the respect between the gender, originates the relevancy of reaching to this subject matter. In Nicaragua every time they increase the numbers of women murdered by his spouses, sentimental ex-pairs and persons near to his environment, for what campaigns are necessary of concientización that they promote the respect and the equity of kind. In some spaces of mass media, political and educational, the violence against the woman has turned into an attractive topic; but this one has assimilated from trite speeches of groups that try to defend his rights. Trying to overturn a bit this trend, and in the audacity, as it was named this one throw, one appeals to the methodology based on the microanalysis of the speech, based on Fritz Schütze's biographical theory by means of the biographical processes structured of men who deprived the women's life, which allows to know the conception of the subjects of study.

Key words: Femicide, behavior, worldview, gender equity, power relations, misogyny.
Palabras clave: Femicidio, comportamientos, cosmovisión, equidad de género, relaciones de poder, misoginia. 


\section{INTRODUCCIÓN}

Comprender las dimensiones del fenómeno del femicidio en el municipio de Managua fue el principal objetivo de esta investigación, el cual se logra desde todas las perspectivas posibles, incluyendo la del agresor que priva de vida a su cónyuge o a una mujer desconocida. El objetivo primordial de comprender los comportamientos de hombres que han privado de vida a mujeres es interesante de sobremanera; es por ello que se decidió conocer la historia de algunos femicidas, a fin de percibir dicho proceder desde una perspectiva holística.

El presente artículo es resultado de una investigación con enfoque mixto. Los relatos de vida de los femicidas que se muestran en este trabajo fueron parte de la fase de la investigación cualitativa; esto permitió plantear tesis conclusivas que luego fueron contrastadas en la etapa cuantitativa, lo que derivó en una estrategia de comunicación para generar un cambio social y cambio de comportamientos a través de las herramientas comunicacionales del C4D (Comunicación para el Cambio Social y Cambio de Comportamientos). Para consignar tal fin, las autoras de esta investigación realizaron un total de cinco entrevistas a hombres que cometieron el delito de femicidio (entendiéndose como la muerte que propina un hombre a una mujer por razones de género); para la presentación del trabajo final, se decidió trabajar y analizar tres de estas.

\section{Metodología para esta investigación}

En la fase cualitativa de la investigación se aplicaron técnicas como la lluvia de ideas con expertos y expertas en el femicidio, y sin duda, la entrevista autobiográfica narrativa con femicidas. La metodología empleada en este proceso se basa en el microanálisis del discurso, fundamentada en la teoría biográfica de Fritz Schütze por medio de los procesos biográficos estructurados. Se contó con el consentimiento de los hombres privados de libertad, quienes desde una de las celdas del Sistema Penitenciario de Nicaragua, activaron su memoria para narrar las etapas de sus vidas y lo que los llevó hasta esos escenarios. A través de entrevistas grabadas, estos relatan momentos de su infancia, adolescencia, juventud y adultez.

Las entrevistas autobiográficas narrativas permiten una visión holística del problema en estudio, ya que en los relatos de los entrevistados se buscan circunstancias de su trayectoria de vida que marcaron su cosmovisionario sobre las relaciones de poder en la pareja y fueron determinantes en la constitución de sus singulares estructuras psíquicas, 
emocionales e ideológicas, como condicionantes de sus actitudes y comportamientos femicidas.

A través del relato de vida de los femicidas se devela la subjetividad que subyace en su personalidad y que es vital para conocer la dinámica de los que ejercen control sobre la mujer. Cabe destacar, que la investigación no se focaliza solamente en la incidencia de las estructuras sociales que favorecen los comportamientos femicidas, sino que considera la perspectiva del sujeto criminal y los factores que determinan su comportamiento.

De la inducción analítica que se obtuvo durante el análisis de la trayectoria de vida de los sujetos de estudio, utilizando la propuesta de Fritz Schütze del análisis biográfico estructurado, resultaron cuatro tesis principales construidas a partir de las similitudes en los comportamientos de los femicidas seleccionados como sujetos de estudio. Muchas de estas tesis conclusivas se lograron corroborar con una técnica cuantitativa, por lo que se demuestra que el sistema patriarcal favorece la ocurrencia del femicidio, así como las relaciones desiguales de poder que benefician al hombre y representan sumisión para la mujer.

De igual forma, la misoginia, constituida como el odio hacia las féminas, es un factor contundente debido al uso de sadismo con el que privan la vida de una mujer; y por su parte, el consumo de alcohol y drogas funciona como detonante para ejercer violencia contra la fémina, lo que condiciona el actuar femicida.

En el transcurso de las entrevistas se procedió a realizar el microanálisis de historias de vida de los femicidas. En este proceso, las tres historias de vida de los sujetos responden a las características claves para el estudio de las dimensiones del femicidio a través de sus relatos. Se presentan las historias de estos sujetos de estudio con sobrenombre para preservar su anonimato.

\section{Presentación del caso de "Juan"}

Se realizó una entrevista a Juan, un hombre adulto de treinta y un años de edad (hasta el momento de la entrevista), quien desde niño sufrió violencia ejercida por su padre. Su familia nuclear estaba compuesta por sus progenitores y sus seis hermanos. A la edad de ocho años recuerda una de las experiencias que, según su relato, lo marcó para siempre, debido a la carga de violencia que fue ejercida contra su humanidad. 
Como un mecanismo de escape a ese círculo de violencia huye de su casa definitivamente a los doce años de edad. Se inserta en un grupo armado delincuencial a los catorce años de vida; posteriormente, es nombrado jefe de pelotón e inicia actividades delictivas.

Procrea cuatro hijas con su primera pareja, de igual forma continúa su vida realizando actos ilícitos y es condenado a treinta años privado de libertad por asesinato atroz. Hasta el momento de la entrevista lleva seis años pagando su condena.

En el análisis del primer segmento narrativo, Juan sufre violencia intrafamiliar por parte de su progenitor, situación por la que justifica el odio contra aquel que le dio la vida.

En su relato, respecto a los sentimientos de odio y deseos de privarle la vida a su progenitor, generado por la formas de crianza, Juan interviene de la siguiente manera:

...yo siempre pensé y manejé esa idea de quitarlo de la vida de nosotros, fui el único de mis hermanos varones que tomó esa decisión, y siempre, este, erróneamente, como todos seres humanos, que erramos en lo que hacemos, en lo que decimos y en lo que pensamos, hasta a veces me sentía hasta como apoyado por mis propios hermanos, tal vez por el trato, que nos daba, ya no soportábamos, ya no aguantábamos un día más, cada día era una tormenta, era un martirio, era un infierno en carne propia, porque no podíamos comer tranquilo, no podíamos andar tranquilo, este; para llamarnos era con violencia, para tratarnos la misma violencia, para todo lo que él se iba a dirigir hacia nosotros era violencia.

La violencia marcó la vida de Juan al sufrir maltrato desde niño por parte de su padre, quien no era alcohólico pero siempre recurría a la violencia como medio eficaz para demostrar que él era quien controlaba y emitía órdenes, mismas que no podían ser contrariadas.

Es importante tomar en cuenta que las huellas que deja la violencia en un niño, es un factor determinante para su crecimiento, debido a que estos se vuelven propensos a desarrollar comportamientos violentos, causados por un modelo de vida. La figura de un padre que debe proteger a sus hijos se fue desvaneciendo ante los ojos de Juan, acuñado por las constantes agresiones físicas y psicológicas, de las cuales también eran víctimas su madre y sus cinco hermanos. 
El punto de fuga ante el panorama de transgresiones que facilitaba la adquisición de esos mismos patrones de comportamiento por parte de Juan hacia su padre, se convirtió en un deseo de privarle la vida, puesto que era la forma más contundente, según sus propias apreciaciones, para colocar el punto final a ese círculo de violencia a los que él, su madre y hermanos eran sometidos constantemente. Esta premisa sobre la violencia vivida por Juan es determinante en la construcción de su personalidad, así como en las acciones que realizara en el transcurso de su vida, principalmente respecto al hecho de la privación de vida de una mujer.

Para este episodio, la violencia percibida por Juan trasciende hasta el género femenino, quien a razón de un infante permitía tanta violencia por parte de su padre: su madre. Ese sentimiento de odio incentivado por razones de género (misoginia) de parte de un hombre hacia la mujer, es contundente en Juan:

... En un momento yo llegué a odiar a mi madre, porque ehh, yo fui creciendo, yo miraba ;chocho!, le decía yo: "si usted está aburrida de tanto dolor y sufrimiento y ha vivido lo que estamos viviendo con mi papa, ¿por qué usted siempre vuelve?”, ¿por qué usted siempre nos permite llegar hasta ese lugar de nuevo y soportar lo mismo? Eso yo no lo comprendía.. Pero llegué un día, y le dije a ella, ya grandecito, ya como a la edad de unos 12 años, que por qué hacía eso ella, que si a ella le gustaba vivir la vida que llevaba, el ritmo de vida que mi papa le daba, y ella me dijo estas palabras " a mí, me dice: no es que me guste el ritmo de vida que tu papa nos da, dice, pero es que yo lo quiero dice, pero tampoco por querer los voy a estar sometiendo tanto, de aquí en adelante yo no vuelvo con tu papa, y no volvió", verdad, pero ya el sentimiento ya había nacido, y yo se lo expresaba: mama "yo la odio a usted, le digo, la odio", no es ni parecido al odio que le tengo a mi papa, pero hay momentos que la odio y siento que sí, la odio, porque usted misma permitía todo lo que mi papa nos hacía.

La madre de Juan es una muestra de la construcción social de lo que significa ser mujer, basada en que debe estar siempre en una posición de subordinación frente al hombre. Además que desde el imaginario colectivo se establece que la violencia es parte de las relaciones de pareja y la mujer debe someterse a esta. Interviene la falta de habilidades psicosociales para romper con el círculo de violencia, pues ante ello, la progenitora de Juan justifica sus decisiones en lazos afectivos con su pareja. Juan relata que su mamá le decía: “... a mí, me dice no es que me guste el ritmo de vida que tu papa nos da dice, pero es que yo lo quiero...". 
Desde la psiquiatría se estudia la relevancia que adquiere la figura materna en los hijos. En este caso Juan desarrolló sentimientos misóginos, porque las emociones de repulsión, enojo, odio, frustración y rencor que sentía por su padre fueron transferidos hacia su progenitora, a causa de la presión interior, provocada por la realidad hostil que le había tocado vivir. Es por ello que la misoginia es una dimensión que condiciona los actos femicidas.

A los catorce años de edad, Juan decide unirse a un grupo armado e inicia en pleno su vida delincuencial:

...Hasta que llegué a la edad de los 14 años, ehh, vine y me ingresé a un movimiento armado que se llamaba FUAC (Frente Unido de Andrés Castro), ehh, en el 94 me metí a eso, en la zona de Estelí, Jinotega, El Cuá y Bocay, con ese Frente de Andrés Castro el FUAC. Allí, ya, a la edad de 14 años que yo me ingresé ahí, ya empecé una vida delincuencial plena en todo el sentido de la palabra, a delinquir como todo un delincuente profesional, alli me fui convirtiendo en lo que ahora soy,... A los 14 años ya me dieron un fusil, ehh, me metieron a las fuerzas de operaciones que ellos tenían, me metieron en un frente, en el frente 31 de ese grupo remanente, y allí me quedé, allí empecé yo, mi vida delincuencial ya en pleno.

Este segmento de vida es trascendental en la formación de la personalidad de Juan. El hecho de ingresar en un movimiento armado a la corta edad de catorce años, es un detonante para la construcción de una conducta violenta, heredada por la lógica autoritaria del poder y la supremacía que es inculcada a los guerrilleros desde la educación militar. Al respecto, Juan refiere: “...yo ya me sentía un guerrillero completo y allí me quedé...”

Las secuelas de una infancia violenta se convierten en una plataforma de la transmisión de los mismos roles por parte de su padre, además de una construcción mental del cómo debía ser un hombre, ejerciendo su voluntad y cumpliendo sus mandatos sin restricción alguna. De igual manera, a las secuelas psicológicas dejadas por estos años de maltrato, se suman las normas y reglas establecidas en un grupo dedicado a realizar actos ilícitos.

La concepción de quitar la vida a otro ser humano formaba parte de las funciones en la tropa, donde se tiene como mejor amigo al fusil y existe, ante cualquier cosa, la ley del más fuerte. Es una sola opción: “o matar o te matan”, dinámica de la cual Juan era parte y la traslada a su historia de vida. Juan narra, al respecto: “...un enfrentamiento en una 
emboscada con el Ejército y la Policía, y convertimos eso en una masacre multitudinaria, de los dos bandos, eso fue lo que más me marcó para siempre en eso...”

Con todo ello, en sus relatos Juan niega haber protagonizado violencia en sus relaciones de parejas. Admite que no desea que su familia sufra lo que él en su etapa de infancia. Esto podría considerarse contradictorio al comportamiento que siempre mantuvo, según su relato, y en sí en su actuar criminal al estar "obligado" a obedecer los mandatos de las actividades como sicario, en este caso particular para matar a una mujer. Él mismo lo deja asentado:

Bueno mirá yo te voy a decir algo, yo estoy por eso y yo no, yo no te pudiera decir algo que no vaya acorde a lo que yo siento que por qué lo hice, me entendés, mirá, en primer lugar yo no tenía ningún motivo, ninguna razón para actuar de esa manera, pero sí fui influenciado, en ese momento no escatimé, no acaparé, ni siquiera me detuve a pensar en consecuencias de lo que iba hacer, porque me sentía que tenía que hacerlo y lo hice, lo hice, erróneamente lo hice.

...solo te puedo decir que cuando uno tiene algo que hacerlo, por obligación lo hace...yo era un subordinado, yo tenía mi patrón, yo trabajaba, ehh y trabajaba en esa materia desgraciadamente, y este, bueno, pues, es algo directo así no más, y ¡hacelo y hacelo!, o sí o sí, pero aquí no más.

\section{Presentación del caso de "Niko"}

Niko, es un joven de diecinueve años de edad (al momento de la entrevista). Se encuentra pagando una condena de once años por violación y asesinato, que cometió junto a un familiar (su primo).

La infancia de Niko transcurrió con normalidad, como califica él mismo. Se crió en una familia con valores cristianos, que educaba a sus hijos a través de consejos. Comenta que en constantes ocasiones, cuando él se iba a las fiestas, en su etapa de pubertad, su madre lo aconsejaba, pero cuando este no los tomaba entonces su mamá y su papá le llamaban la atención; sin embargo, cuando ya no quería entender, sus progenitores tomaban la decisión de castigarlo con "faja o una tajona" para hacerle ver que no era bueno que anduviera de vago. Es el menor de nueve hermanos, condición que lo hace meritorio de atenciones y mayores cuidados en su seno familiar.

Al revelar que su infancia transcurrió con mucha tranquilidad, es muy poca la inferencia que se puede hacer de esa etapa. Asimismo, de su etapa adolescente y adulta, 
tampoco hay muchos insumos, ya que a su escasa edad infringe la ley y es privado de libertad. Esta situación lo hace recapacitar, creando en él valores de responsabilidad para no cometer otro "error", como él mismo llama, y así dirigirse en la vida como un mejor ser humano.

El grado de timidez de Niko expresado a través de su kinestésica, fue marcado durante la entrevista, pues este se mostró muy nervioso durante el proceso de la conversación. Sentado en su banquito, fueron raras las veces que mostraba su rostro a las interlocutoras. Los movimientos como el que le temblara la pierna derecha, las manos empuñando el banquito y el sonido de sus dedos al forzarlos, son elementos que delatan su estado de nerviosismo ligado a su personalidad introvertida.

Junto a su primo, por el lapso de tres meses premedita la violación de una joven; pero durante el hecho, deciden trascender el delito y perpetrar la muerte:

Pues como que ya lo tenía un poco planeado él ya, y solo que me daba indicaciones: “mirá ahí pasó ahorita, me decía. Entonces qué nota perseguimos y yo le digo no, no está bien meterse a un clavo de esos, vos sabés, le digo; no hombre y quién se va dar cuenta.

...Pues, lo planeado porque al bróder le prestaban una bicicleta, ya, tonce (entonces) me decía ya tenemos la nave lista me dice, hay que darle talón (violarla) a la que te dije me dice. Ay veces yo retrechero pues, porque yo no quería meterme, meterme en ese juego. Ya sabía que era algo muy, que me iba a meter en una consecuencia de que después me iba a arrepentir. Entonce el, dimos persecución ese día, y en varias ocasiones, pues, le habíamos dado persecución pero habíamos fallado y ese día me dijo que no falláramos, no quería fallar, entonces yo le dije que no se preocupara, que iba a tener mi apoyo y caí en el error pues de...

En la trayectoria biográfica de Niko se logran definir cuatro grandes categorías que condicionan su comportamiento. La primera es la formación bajo principios cristianos, cultivados por su madre, lo que se reproduce, según considera él mismo, en una estabilidad emocional en su niñez y una infancia sin violencia. La segunda categoría es la falta de habilidades psicosociales para enfrentarse a la presión social generada por su grupo de amigos. Asimismo, se condiciona por la construcción de la personalidad en una etapa de ebullición, la adolescencia, en la que se generan cambios físicos y emocionales, razón por la cual se dificulta poner en práctica la asertividad, con respecto al manejo de las emociones. 
Una tercera categoría se condiciona por el descubrimiento de una sexualidad temprana, haciéndose responsable la crianza de dos hijos, situación que le infunde interés por implementar un grado de madurez y dejar el mundo de "vagancias" en el que se encontraba.

En cuarto lugar está la presencia de patologías de comportamiento o conductuales, puesto que la forma como se maneja frente a los momentos de presión de amigos tiene alguna relación con el poco autocontrol de las emociones. Específicamente, esta afirmación se constituye a raíz de dos presupuestos: la primera es su forma de ser, parece ser una persona tímida, que esconde algo; muestra de ello es que sus ojos nunca develan la total franqueza de lo que articula en su discurso biográfico. Aparenta ser alguien introvertido, una persona reposada que no sería capaz de ejercer violencia.

Por otro lado, el presupuesto en el que se basa, es el comportamiento que adopta a propósito de la planificación del acto de violación, que si bien es cierto desde su relato maneja que su acompañante (su primo) era el que por instintos morbosos y de poco control de pulsiones sexuales, deseaba realizar este hecho, resulta paradójico que lograra soportar esa situación, cuando en casos anteriores se había dejado llevar por influencia de sus amigos para realizar otro tipo de actos.

En la primera categoría se demuestra que la etapa de la infancia no tuvo mayor repercusión en la vida de Niko. Aunque bien podría ser que la falta de diálogo para conversar abiertamente sobre la sexualidad, condicionado por la religión a la que pertenecía su mamá, haya sido una de los causantes de que este se convirtiera en un padre adolescente. Es importante reconocer que la falta de manejo de las emociones y los conocimientos sobre la dinámica de las relaciones sexuales condicionó un embarazo no deseado de su pareja.

En el segundo caso, la falta de asertividad para poder tomar decisiones sobre lo que era más conveniente para su futuro es evidente, porque es probable que por querer ser aceptado por el grupo y experimentar su condición, accedía a tener una conducta anárquica y de total rebelión contra las órdenes de su madre.

La situación que genera un cambio en la adolescencia de Niko, es la responsabilidad de ser padre de dos niños, la incertidumbre de modelos de aprendizaje, el ejemplo de vida que les permitirá continuar con los patrones aprendidos, son las razones por las que Niko decide concretar un antes y un después en su crecimiento individual. 
En el caso de la cuarta categoría ya ha sido descrita ampliamente, situación que se confirma también por la observación directa que se realizó a lo largo de la entrevista con cada uno de los sujetos de estudios, de los cuales se tiene características específicas de Niko que contribuyen a lo antes mencionado.

Es conveniente saber que dentro del discurso estructurado de Niko se logró identificar algunas contradicciones o discrepancias, interrogantes que él mismo se plantea desde su propio constructo de comportamiento o bien que divergen entre los hechos, los pensamientos o las razones del porqué llevó a cabo tal acción.

La primera paradoja en la que se sitúa Niko es el hacer caso omiso a las reglas impuestas en su casa, el saber desde su base de conocimientos aprendidos que no debía realizar tales actos, como irse a fiestas, pelear con las personas por causas ajenas, poner en riesgo su vida por entablar amistades con individuos de poca confianza, que sólo recomendaban el hacer valer en los padres los derechos de los hijos, desde una lógica rebelde.

Su posición es contraria desde su actuar, porque en su discurso declara que le gustaba este nuevo estilo de vida que comenzaba a llevar al lado de sus amistades; no obstante, sabía que no estaba realizando lo correcto, además que recaía en el sentirse culpable, por la incertidumbre que causaba en su madre, expresada en los consejos que le dirigía, así como de las medidas correctivas de golpes, como último recurso para hacerlo reflexionar.

La otra disyuntiva en la que se ubica a Niko es el apoyar a su primo en el acto de violación de la joven. En su discurso, este plantea que lo concebía como una locura, ya que estaba consciente de que no se debía hacer y que obligatoriamente significaba un problema que no solamente lo afectaría a él, sino a toda su familia.

Niko se cuestiona y reconoce que es un error haberlo realizado, pero a la vez encuentra una razón más poderosa para apoyar a su primo, probablemente el deseo de satisfacer su curiosidad sobre el qué se sentía tomar a una mujer a la fuerza; sin embargo, desde su propia interioridad vivía sumido en un diálogo, por una parte, el saber que estaba prohibido y por el otro lado los instintos que de forma latente, estaban en su indagatoria.

"Pues, era solo abusar de ella, abusar, violar, entonce como le quieran llamar ya eh, peroo llegó en el término como que le entró la lujuria al maje y como que me dijo que mejor la matáramos, entonce yo le dije que estaba loco, entonce me dijo que el loco 
era yo, que si ella se daba cuenta nos iba echar preso; entonce le digo que las cosas se iban agravar más, que era otro clavo, entonce me dijo él que a él no le importaba, a mí sí le digo, porque vos sabés que tengo hijos, tengo a mi madre, yo también me dice ¡ideay! Pero me decía él, ahora ya estamos en el punto, hay que hacerlo me dice, hay que eliminarla porque nos puede crear problema. Si ella nos reconoce, nos puede matar o nos puede echar preso".

Respecto a la personalidad de su primo, quien fue el autor principal del crimen, Niko contesta:

Pues era, él era tranquilo, salía conmigo, pero nunca me había, me había dicho eso, nunca me había tocado ese tema, pero cuando yo ya me metí con esa persona que, que convivía entonce como que él se sentía solo porque ya no tenía la misma amistad con otra persona que conmigo. Entonce cuando ya me dejé con ella ya comenzó a decirme cosas, que mirá que fijate que así, jideay! ya vos tenés tu jaña, ya vos agarrá y yo no entonce y le digo: no hablás, no agarrás, le digo; y yo ya sabía su matice de él, que era muy tímido, ya, tonce ya me contó que, que quería agarrar una mujer a la fuerza, que, que, que se sentía que. Tonce, yo me ponía a sonreír porque no jva! esa es una de las locuras más grandes, le digo yo. Ay veces así, mejor le digo yo vamos a Granada buscá El Tero (prostíbulo de esa ciudad) y no vas a, a echarte un clavo encima le digo ¡ideay! y no me vas a meter en clavo a mí también, le digo y a mi familia y a tu familia...

Otra de las contradicciones, encontradas mediante el relato de vida de Niko, es que él declara que los celos permiten que una mujer sea víctima de femicidio si le es infiel a su cónyuge, quien no puede concebir la idea de que una mujer, a la cual considera de su propiedad, lo traicione. En contraposición y desde un sistema patriarcal, Niko considera que los hombres no deben ser víctimas de celos por parte de sus parejas, puesto que los “gobernadores" tienen la potestad de poseer cuantas más mujeres estén a su alcance sin que esto se les señale.

\section{Presentación del caso de "Alberto"}

Alberto es un adulto de treinta y ocho años de edad (hasta el momento de la entrevista). Nació en la ciudad de Diriá. Tiene treinta y cinco hermanos, ocho de parte de su mamá, dos de parte de padre y madre y otros veintiocho que no conoció. Careció de una figura de padre y padrastro, puesto que cuando su mamá tuvo un compañero dejó a su hermana de ocho años y a él de siete, al cuido de su abuelita, quien habitaba junto a una tía y un tío. 
Durante ese tiempo, asegura Alberto, no le hizo falta cariño ni amor de su madre ni de su padre, porque lo obtuvo de su abuelo y abuela. Además de lo material, no le hacía falta nada, "todo lo tenía", pues sus abuelos les ofrecieron, a él y a su hermana, todo lo necesario. A la edad de dieciséis años tuvo su primera novia de veinticuatro años de edad, esta era una mujer inestable porque tenía otras parejas, paralelas a la relación que mantuvo con Alberto, por lo que él aprende a tener ocho novias al mismo tiempo.

Además, mantuvo relaciones sexuales con gais, en unas tres ocasiones, porque, según él, eran situaciones que le salían de repente sin andar en busca de las mismas. A los diecisiete años permanece por dieciocho meses en el servicio militar, lo que lo convirtió en un hombre violento porque aprendió que a quien se le ponga en frente lo debía agredir. Relata que en situaciones de pleitos entre sus amigos, él era quien salía a la defensa.

Dejó de vivir en casa de sus abuelos cuando fallece su abuela. Se compromete con la mujer que era diez años mayor que él a quien le priva de la vida. A esta la conoce en el sistema penitenciario, cuando tenía veintiséis años de edad, al ser apresado tras mantener un pleito "verbal" con sus amigos. Durante su estadía en la cárcel la conoce y luego formalizan su relación en unión de hecho. Permanecen juntos durante nueve años.

El microanálisis del relato de vida de Alberto, permite comprender las categorías analíticas de las dimensiones del fenómeno de este femicidio como factores institucionalizados que dictan patrones de conducta en el imaginario colectivo de la sociedad nicaragüense en donde radica el machismo.

Por un lado, el papel de las abuelas, de criar a sus nietos, ante la ausencia de la figura paterna de los niños, luego de la separación de los padres. Asimismo, la concepción machista del hombre al tener muchas relaciones para sentirse superior y "macho" ante los demás varones, y por otro lado, las relaciones sexuales de adolescentes con gais, en búsqueda de identidad:

A ver, lo que pasa es que, (titubea), en, en mi juventud tuve también relaciones no buenas, porque uno joven es loco, uno comete locuras, errores, hasta cuando uno llega a una etapa que uno comienza a analizar, entonces uno dice "chocho", yo hice tales cosa, si no no lo hubiese hecho, si por eso Dios manda a la dama para estar con la dama. Sí, tuve relaciones, con, cómo le podría llamar con geises (homosexuales), sí, tuve relaciones con gay, no muchas, unas, dos, tres veces, pero después me arrepentí, 
y dije yo que era malo, porque comencé a leer la Biblia, y la Biblia habla muchas cosas buenas, ay ta (ahí está) el mejor consejo, y yo dije, que me perdone por lo que hice, cometí esos errores, uno se arrepiente y la meta es no volver a cometer el error, y eso es lo que hice. []...Antes, en mi vida de loquito, de los 16 a los 22 años, en ese trayecto hice esas locuritas, no las volví a cometer porque me di cuenta, que es malo.

A través del relato de vida de Alberto, se devela una construcción patriarcal de concebir a las mujeres como seres débiles e inferiores al hombre, ligado a ello, a través de su relato se infiere una conducta violenta tras los meses en el servicio militar:

Sí, era pleitisto, pero en mi juventud, en esa etapa de poco de novias, si era bien pleitisto. Cuando yo vine del servicio militar, porque sólo estuve 18 meses en el servicio militar, a mí me llevaron mmm, iba a cumplir diecisiete años, en ese entonces, como siempre he sido así, como un poquito recio y allí me hice todas estas locuras que me miran aqui en la mano (son tatuajes). (...) ;Duro eso! (respira profundo), duro, porque en ese entonces, cuando yo entré en el servicio fue fuerte, bueno tal vez han escuchado la historia del Danto 88, fue un combate con la contra y los cachorros bien fuerte en esa época, el 88 ”.

En este segmento narrativo, Alberto manifiesta que el servicio militar lo hizo ser una persona nefasta y pleitista, pues fueron concepciones aprendidas en este período de su vida. Además, es un momento que marca su trayectoria, porque a partir de ahí concibe una visión del mundo en defensa de su existencia, porque debe disparar un arma antes que alguien se le adelante. Y precisamente, de esa forma es que ultima la vida de su víctima, circunstancia que él justifica:

“...Que si alguien se para en frente lo tenemos que bajar de ahí. Si, mejor dicho, allí estamos hablando del servicio militar, alli el enemigo y supuestamente los cachorros, bueno, que éramos nosotros, ambos nicaragüenses, ambos seres humanos, para mí, nunca estuvo bien que yo derribara a otro ser humano y tampoco no me gustaba que me hicieran algo; entonces la técnica que ellos usan, es que tu fusil es todo y que con ese te vas a defender y que el que se para en frente, ese se va, mejor dicho es una mentalidad mal, por eso muchas personas solo piensan en eso, en matar, porque la mayoría tuvieron allí, todos, mejor dicho de aquí de Nicaragua, la mayoría estuvo en ese servicio militar, y el entrenamiento que dan, que daban los cubanos en ese entonces eran sólo de muerte, matar, y hay mucha gente que se quedan con esa mentalidad en la mente, no miran más allá, que no debe ser así”. 


\section{Del análisis de sus relatos}

De cada una de las entrevistas autobiográficas narrativas se indujo las siguientes categorías y subcategorías como constructos integradores de las dimensiones del femicidio.

Entre las características homogéneas que se perciben en los relatos de vida de los sujetos de estudio, se encuentra una construcción patriarcal, en la que destacan los estereotipos de hombres y mujeres que marcadamente guardan su asignación de roles, mismos que desde una perspectiva machista imperan en la educación brindada por la familia, principalmente a través de los modelos madre-padre como ejes fundamentales de la formación conductual, además de la impronta que deja la inserción en grupos armados regulares o irregulares, ya que en estos imperan sistemas autoritarios.

El sentido de pertenencia del cuerpo de las mujeres es una de las características comunes de los tres casos estudiados, porque todos consideran que la mujer es como un objeto del hombre. Los celos son parte de los medios para controlar y dejar claro el sentido de posesión sobre la mujer; sin embargo, otros como Alberto lo expresan a través de la compañía perenne con la mujer, o bien en el caso de Juan la solución se limita a dos opciones: la muerte o estar con él.

La misoginia es un factor contundente, en los casos de Juan y Niko. Esta se evidencia en la forma del cómo planificaron y perpetraron el hecho; sin embargo, el caso desviante es el de Niko, el cual presenta una dimensión patológica, proyectada a través de su personalidad introvertida y misteriosa, lo que contradice el comportamiento de desafuero sexual y violación cometida. Por su parte, Juan no tenía ningún interés en su víctima de femicidio; su comportamiento respondía a su "trabajo" como sicario; no obstante, la descripción de lo ocurrido deja al descubierto un comportamiento misógino.

Esta característica ubica a Juan como el caso único, en cuanto a las razones del por qué cometió el hecho, lo que forma parte de nuevos contextos del femicidio, ya que la muerte no solo implica un deseo sexual o relaciones desiguales de poder, sino que responde a intereses de otra índole, o bien por conveniencias individuales o de una colectividad criminal.

Otra similitud es que las adicciones marcan la pauta de situaciones de riesgo, como la inserción a grupos juveniles, factor que se señala en el caso de Niko, el cual carece de habilidades psicosociales para enfrentarse a la toma de decisiones en su adolescencia. Juan y 
Alberto también se inician en el alcohol, el primero para evadir su realidad de vivir sometido a violencia intrafamiliar, mientras que el segundo en una etapa de desarrollo en su vida.

Estas dimensiones, a su vez, se convierten en factores que condicionan los comportamientos de los hombres femicidas:

1. Los celos como método de control en las relaciones de parejas; 2. El papel de las abuelas, de criar a sus nietos, ante la ausencia de la figura paterna de los niños, luego de la separación de los padres; 3. La concepción machista del hombre de tener múltiples parejas simultáneamente para sentirse superior y "macho" ante los demás varones; 4. Relaciones sexuales de hombres adolescentes con homosexuales como una práctica de búsqueda de identidad; 5. Una construcción patriarcal de concebir a las mujeres como seres débiles e inferiores al hombre; 6. El consumo de drogas y bebidas alcohólicas como una nueva experiencia; 7. La toma del control absoluto de parte del hombre en la relación, realizando inclusive labores domésticas para satisfacer a la mujer y ejercer control sobre ella; 8 . Tolerancia y legitimidad de la violencia intrafamiliar en la sociedad nicaragüense; 9. El uso de la violencia como condición correctiva para educar a los hijos e hijas; 10. La construcción de la feminidad desde una perspectiva machista, en la que la mujer debe ser sumisa y soportar al marido hasta que la muerte los separe; 11. Generación de misoginia o sentimientos de odio hacia las madres por el hecho de ser mujer; 12. El autoritarismo respalda sistemas patriarcales que intervienen en contextos de violencia; 13. El poder y los celos son medios de dominación sobre los cuerpos de las mujeres; 14. La reeducación penal no es garantía de cambios de comportamientos en los femicidas; 15. La concepción social de que una persona criada bajo principios cristianos debe conducirse bien en la vida; 16. La noción de mimar a los hijos menores, quienes en lo general adoptan comportamientos de timidez y apego hacia sus progenitores; 17. La presión social que se ejerce dentro de los grupos, para poder pertenecer a ellos; 18. Formación de la personalidad, conflictos emocionales, cambios físicos y psicológicos desde la etapa adolescente; 19. La displicencia de los padres adolescentes con respecto a la responsabilidad de la crianza de los niños; 20. Patologías de cada ser humano, que condicionan el actuar femicida; 21. La violación sexual como una de las formas más comunes de ejercer violencia; 22. La concepción machista que considera que los celos son uno de las mayores condicionantes para justificar el asesinato de una mujer. 


\section{Tesis conclusivas}

Los análisis biográficos estructurados resultantes de los puntos coincidentes en las tres entrevistas, permiten resumir tesis conclusivas como síntesis de los hallazgos. En estas se remarca el sistema patriarcal que se sustenta en una ideología de subordinación exclusiva, basada en la desigualdad en las relaciones de poder entre hombres y mujeres. A continuación se especifican:

1- La construcción de estereotipos, en los que se cree que los hombres gobiernan y las mujeres deben obedecer sus mandatos, condiciona la posición de subordinación de esta frente a la actitud machista del hombre, respaldado por una concepción patriarcal de ambos géneros.

2- La ideología en que se basa la desigualdad entre hombres y mujeres está dada por la lógica de quien detenta el poder es dueño del cuerpo femenino; es decir, el sentido de pertenencia que se crea en los hombres.

3- El odio a la mujer se evidencia en la saña, planificación, violación sexual y formas crueles con que son perpetrados los hechos: misoginia.

4- El licor en conjunto con otras sustancias condicionan la conducta violenta del femicida, algunos de ellos encuentran en estos, alivios a situaciones de violencia en su infancia, lo que a su vez agrava las dimensiones del femicidio.

Antes de concluir, es muy válido reflexionar sobre la importancia de la aplicación de la metodología de la Historia oral para este estudio, que hizo posible obtener la experiencia de los informantes quienes atestiguaron sobre tales acontecimientos; sin duda alguna, de otro modo no se hubiese conseguido. Como punto final, se presenta el siguiente gráfico en representación de la ruta de violencia, respecto a los modelos de crianza que forjaron la personalidad de los tres victimarios. 


\section{Ciclo de victimarios}

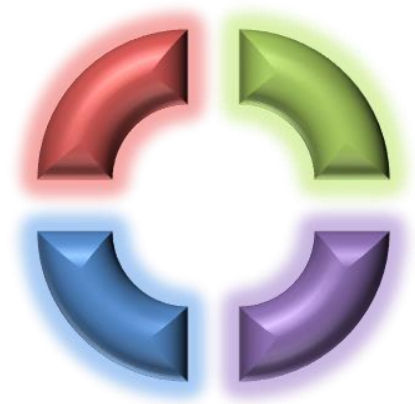

Estereotipos de género

国entido de pertenencia

Misoginia

Adicciones

\section{REFERENCIAS}

Álvarez M. et al. (2010) El femicidio en Nicaragua. Abordaje y propuesta de indicadores para la acción. Managua: PATH-Intercambios.

Carcedo, A. (2010) No olvidamos ni aceptamos: Femicidio en Centroamérica. (2000-2006). Costa Rica: Asociación Centro Feminista de Información y Acción, CEFEMENINA.

D’Angelo. A, Molina. Y (PATH), Jubb. N (CEPLAES) (2008). Mapeo de las Comisaría de la Mujer, la Niñez y la Adolescencia. (CMNA). Managua, Nicaragua: Dirección Comisaría de la Mujer y la Niñez.

Foucault, M. (1998) Historia de la Sexualidad I. La Voluntad de Saber. México: Siglo XXI de Editores, S.A.

Wilber, K. (1997). Breve historia de todas las cosas. Barcelona: Editorial Kairós.

Comisión de género de la Corte Suprema de Justicia (CSJ), (2010). Política de género: Fondo de Población de Naciones Unidas UNFPA.

Corte Suprema de Justicia (CSJ), (2011). Dictamen de Ley integral contra la violencia hacia la mujer.

UNICEF. (2011). Estrategia de Comunicación para eliminar la Violencia contra niños, niñas y adolescentes. Managua, Nicaragua: UNICEF.

Corte Suprema de Justicia (CSJ) (2011). Aprendiendo con Don Justino.

Movimiento de Mujeres María Elena Cuadra (2011) Misoginia y prácticas. Caso Nicaragua. 
Movimiento de Mujeres María Elena Cuadra (2011) Misoginia y todas las formas de violencia contra las mujeres.

El problema de las dimensiones subjetivas. Recuperado de http://www.psicologiaonline.com /pir/apuntes/el-problema-de-las-dimensiones-subjetivas.html)

Conceptos y artículos de la mujer. Recuperado de: http://www.ciudaddemujeres.com

Violencia de género y misoginia: Reflexiones psicosociales sobre un factor explicativo. Recuperado de: www.nodo50.org/mujeresred/violencia-bosc-ferrer- 2.html

Violencia de género en Nicaragua: Los femicidios aumentan y 2010 termina con 89 mujeres muertas. Recuperado de: redesdesolidaridad.wordpress.com/.../violencia-de-genero-ennicaragua.

Informe Anual Femicidio-Feminicidio-Red de Mujeres Contra la Violencia. Recuperado de: $\underline{\text { www.reddemujerescontralaviolencia.org.ni }}$ 